\title{
UM OLHAR SOBRE HISTORIOGRAFIA E EPISTEMOLOGIA NO CAMPO DA CIÊNCIA DA INFORMAÇÃO
}

\author{
Isa Maria Freire ${ }^{1}$ \\ Universidade Federal da Paraíba \\ isafreire@globo.com \\ Tiago José da Silva ${ }^{2}$ \\ Secretaria de Educação do Estado de Pernambuco \\ tiago.stalin@gmail.com
}

\begin{abstract}
Resumo
Investiga a produção científica na temática Epistemologia e Historiografia da Ciência da informação a partir dos Anais do Encontro Nacional de Pesquisa em Ciência da informação, de dados da Plataforma Lattes e da literatura indexada na Base de Dados da Ciência da informação. Identifica o coletivo de pesquisadores que dão continuidade e consistência ao trabalho epistemológico e historiográfico da área. Destaca, na temática abordada, um grupo que consegue produzir mais que a maioria dos demais pesquisadores. Pesquisadores com alunos na pós-graduação tendem a publicar mais artigos em colaboração do que os outros autores que se não encaixam nesse perfil. Os resultados permitiram a descrição de perfis de pesquisadores a partir de um recorte. Conclui que as pesquisas sobre a referida temática, alinhadas aos preceitos dos estudos métricos, podem permitir o desenvolvimento de teias conceituais e metodológicas da Ciência da Informação.
\end{abstract}

Palavras-chave: Ciência da Informação - Epistemologia. Ciência da Informação - Historiografia. Ciência da Informação - Estudos históricos e epistemológicos. Ciência da Informação - Comunicação científica.

\section{A LOOK AT HISTORIOGRAPHY AND EPISTEMOLOGY IN THE FIELD OF INFORMATION SCIENCE}

\begin{abstract}
This thesis research investigates the scientific production about the Epistemology and Historiography of Information Science from the communications of Encontro Nacional de Pesquisa em Ciência da informação (ENANCIB), datas from Plataforma Lattes and the indexed literature in the Base de Dados da Ciência das Informação (Brapci). It identifies the collective of researchers who provide support, continuity and consistency to the epistemological and historiographic works of the area. The results indicate that collaborative relationships in articles are made, most of the times, from the guiding and guiding relationship. Most strictu sensu graduate research projects have mostly worked on the subject matter on the screen. The results allowed the description of the profiles of researchers from a clipping. It concludes that the research on this subject aligned with the precepts of the metric studies can allow the development of conceptual and methodological webs of Information Science.
\end{abstract}

Keywords: Information Science - Epistemology. Information Science - Historiography. Information Science Historical and epistemological studies. Information Science - Scientific Communication.

\footnotetext{
${ }^{1}$ Doutora e mestre em Ciência da Informação pelo convênio entre o Instituto Brasileiro de Informação em Ciência e Tecnologia e a Universidade Federal do Rio de Janeiro.

2 Doutor em Ciência da Informação pela Universidade Federal da Paraíba (UFPB) e Mestre em Ciência da Informação pela Universidade Federal de Pernambuco (UFPE).
} 


\section{INTRODUÇÃO}

As áreas científicas estabelecem, dentro de seu escopo de abrangência, o interesse por metainformações acerca de seus próprios preceitos epistemológicos, no intuito de perceber como, ao longo do tempo, os movimentos culturais, sociais, políticos e científicos constituíram seus objetos, teorias, sujeitos e metodologias. Em outras palavras, as ciências formam grupos de pesquisa/trabalho que evidenciem a importância de conhecer a sua episteme.

A Ciência da Informação, considerada uma ciência relativamente nova e classificada como uma ciência social, tem em seu escopo uma discussão interna em relação ao seu enquadramento dentro do modelo científico. Há uma vertente que segue a linha positivista, a qual, por sua vez, internaliza todas as características desse modelo como "a explicação como sinônimo de simplificação, a quantificação, a busca por regularidades e leis e o consequente apagamento das singularidades", como apontou Araújo (2009, p. 203).

Mas, ao seguir essa linha de raciocínio, tem-se certas limitações quanto às reflexões teóricas, discussões acerca do conceito de informação e percepções empíricas das pesquisas. Ao longo do tempo, surgiu outra corrente teórica que tenta incorporar a complexidade, permitindo capturar "aquilo que o método não dá conta de apreender: a informação subjetiva, dotada de sentidos diversos e inserida no terreno da experiência histórico-cultural" (ARAÚJO, 2009 , p. 203). Nesse contexto, o estudo sobre a epistemologia é muito importante para a Ciência da Informação, pois, segundo Rendón Rojas (2008), permite encontrar a identidade da área e criar um corpo conceitual claro e definido, mantendo relações interdisciplinares.

Para observar o campo científico da Ciência da Informação, a Associação Nacional de Pesquisa e Pós-Graduação em Ciência da Informação (Ancib) criou o Grupo de Trabalho 1 (GT-1), denominado Estudos Históricos e Epistemológicos da Ciência da Informação, que se preocupa com a constituição do referido campo e suas questões epistemológicas. Outro instrumento utilizado pelas instituições hegemônicas da área é constituído pelos periódicos científicos especializados que, no caso desta pesquisa, são aqueles indexados na Base de Dados da Ciência da informação (Brapci). Todos esses dispositivos são responsáveis pela disseminação discursiva, como diz Foucault (1999), em prol do que consideram certo e compatível com os interesses da área, decretando seu conceito e quem pode falar em nome dessa área.

Quando se trata de epistemologia, estuda-se a construção do conhecimento, e essa ação dentro da Ciência da Informação permite conhecer o pensamento científico da área e a construção de seus conceitos, levando à concepção de como as bases teóricas foram fundadas 
e quais foram os métodos que permitiram as definições conceituais. Dessa forma, dentro dos objetivos desta pesquisa, foram estudadas as particularidades dos elementos que intervêm na produção científica acerca da epistemologia da Ciência da Informação no território brasileiro, tomando como partida:

(a) o núcleo de pesquisadores que publicaram nos anais do GT-1 - Historiografia e Epistemologia da Ciência da Informação, nos Encontros Nacionais de Pesquisa em Ciência da Informação (Enancib);

(b) o núcleo de pesquisadores que publicaram artigos indexados na Brapci, buscando os indícios que permitem identificar o núcleo geral epistemológico e historiográfico da ciência da informação no Brasil.

As pesquisas do gênero "dissertação sobre o GT-1 da Ancib" estão restritas a dois trabalhos. O primeiro é o de Nunes (2009), que reflete sobre o desenvolvimento das pesquisas e o avanço do pensamento científico da área da Ciência da Informação a partir da fragmentação da ementa do GT-1 em sete categorias, nas quais foram classificados os 98 trabalhos até então publicados no grupo de trabalho. Isso levou a autora a concluir que o GT-1 é um espaço propiciador de avanços sobre o pensamento científico da área e desempenha um papel fundamental no desenvolvimento do campo. Este trabalho motiva a presente pesquisa, no sentido de dedicar atenção às necessidades que o campo demonstra e à percepção dos rumos tomados pelas pesquisas publicadas nos anais do referido GT.

O segundo trabalho foi desenvolvido por Lima (2017), que faz uma análise discursiva a partir do GT-1 do Enancib. A autora conclui que a institucionalização cognitiva e social tem o poderio de ressaltar a opacidade da institucionalização científica, sendo essa responsável e refém das próprias enunciações. A autora motiva esse trabalho ao defender que para tirar o tema "epistemologia" da periferia da Ciência da Informação é preciso investigar uma nova camada da comunicação científica, levando em consideração que os anais de eventos representam um nível de formalidade equivalente ao dos periódicos científicos, devido à sua institucionalização pelas sociedades científicas.

Freire (2008), ao fazer uma pesquisa exploratória sobre a produção científica brasileira na temática "Epistemologia da Ciência da Informação", a partir dos anais do GT-1 e periódicos indexados na Brapci, conclui que a temática do GT-1 é um padrão que permite o elo entre os fios conceituais e institucionais da Ciência da Informação. Esse trabalho é um dos raros encontrados que utilizam a Brapci na busca de artigos epistemológicos e historiográficos da área. A autora justifica a pesquisa ao dizer que é necessário desvendar as redes de relações institucionais e interpessoais, "subjacentes aos processos de produção e comunicação científica, 
as fontes de informação que alimentam os processos de construção e reconstrução do conhecimento, as redes de citações, que reúnem e entrelaçam antigos e novos conceitos" (FREIRE, 2008, p. 28-29).

Em outra pesquisa in loco, fez-se uma busca na Brapci com os seguintes descritores temáticos: historiografia, historiografia e ciência da informação, epistemologia, epistemologia e ciência da informação. Nos resultados apresentados, apenas um autor transita entre historiografia e epistemologia da Ciência da Informação. Percebeu-se, também, que há uma grande dispersão de autores, além de problemas na recuperação com os referidos descritores, trazendo trabalhos que não tratam de fato da temática, ou apresentando falta de pesquisadores que trabalham a temática, mas que não foram recuperados.

Diante dessas situações, é necessário entender o porquê de apenas um pequeno grupo de pesquisadores manter regularidade nas publicações em anais do Enancib e em periódicos indexados pela Brapci e como se dão as relações entre os pesquisadores dessa temática. Assim, tomam-se como indagações norteadoras da pesquisa, os seguintes pontos:

- Quais pesquisadores mantêm regularidade na publicação sobre a temática "Epistemologia e Historiografia da Ciência da Informação" em anais do GT-1 do Enancib e em periódicos indexados pela Brapci?

- Quais periódicos indexados pela Brapci publicaram trabalhos desses pesquisadores acerca da temática "Epistemologia e Historiografia da Ciência da Informação"?

- Os pesquisadores que publicaram nos anais do GT-1 do Enancib e nos periódicos indexados na Brapci estão vinculados a quais instituições?

- Como se estabelecem as relações entre os pesquisadores da temática?

Nas palavras de Martins (2013), ao se analisar a produção científica de uma determinada área do conhecimento tem-se um instrumento que permite perceber, ou não, ocorrências de estruturas, dinâmicas, tendências e movimentos sociais. Nesse sentido, esta pesquisa se justifica, nas palavras de Duarte (2003), quando aponta para importância da realização de estudos que evidenciem a produção científica, pois estes permitem que se faça um mapeamento das contribuições, dos déficits e das necessidades nas divers as áreas do conhecimento científico, além de permitir a formulação de indicadores que subsidiem políticas de pós-graduação.

Mas, nessa estrutura de produção e comunicação científica, há uma luta coletiva pelo domínio do discurso, como abordado por Bourdieu (1983), de modo que existem as relações de poder institucionalizadas na organização de grupos de pesquisa, programas de pós-graduação, corpos editoriais e redes de colaboração científica. Entender como essas relações se 
estabelecem no campo dos estudos da temática da epistemologia e historiografia da Ciência da Informação parece ser uma proposta interessante para um estudo da dinâmica desses estudos. Para compreender essa estrutura, adota-se uma abordagem que indaga acerca da unicidade ou pluralidade das verdades disseminadas dentro da estrutura do campo.

Diante disso, acredita-se que a pesquisa poderá contribuir para identificar o grupo de pesquisadores que trabalham nessa temática com certa regularidade e descrever as relações estabelecidas na rede de colaboração.

\section{EPISTEMOLOGIA E HISTORIOGRAFIA NA CIÊNCIA DA INFORMAÇÃO}

Ao longo de sua história, a Ciência da Informação vem construindo sua própria identidade, que gira em torno de sua estrutura teórico-metodológica. Foucault (1999) aponta para a identidade como um construto de relações de forças em um determinado período histórico. A identidade, assim, está relacionada a um sujeito, neste caso a Ciência da Informação, e não a um objeto. Desse modo, a identidade dessa área pode ser vista como uma complexidade inerente às novas ciências surgidas no século $\mathrm{XX}$, o que lhes permite um comportamento camaleônico, como pode ser visto nos paradigmas da Ciência da Informação apontados por Capurro (2003), que sugerem que essa ciência se comporta, em relação ao seu objeto de estudo, de acordo com o momento histórico.

Com relação ao objeto informação, conforme Capurro e Hjørland (2007), a Ciência da Informação tem se voltado para a observação da relevância do fenômeno e a sua interpretação como aspectos básicos do seu conceito. No entanto, no seu percurso teórico-conceitual, a Ciência da Informação passa pela complexidade dos problemas relacionados ao seu objeto de estudo, pois este é trabalhado em várias áreas dos domínios, cabendo a ela, segundo Kobashi e Tálamo (2003), determinar qual o seu papel frente à relevância sociopolítico econômica da informação, elaborando conceitos que contribuam para o entendimento do seu objeto de estudo e proposição de alternativas compreensivas do fenômeno informação.

No processo de compreensão do que constitui a Ciência da Informação, faz-se necessário perceber os processos sociais, políticos, históricos, econômicos e ideológicos subjacentes ao seu desenvolvimento. Dessa forma, pode-se verificar sua estruturação, institucionalização e suas contribuições para o desenvolvimento da sociedade e da ciência. 


\subsection{HISTORIOGRAFIA DA CIÊNCIA DA INFORMAÇÃO}

Quanto à sua gênese, existe um embate na Ciência da Informação. Para alguns autores, essa ciência surgiu no período da Segunda Guerra Mundial (BARRETO, 2002; RABELLO, 2008; SARACEVIC, 1996); para outros (MATTELART, 2002; FIGUEIREDO, 1996; ORTEGA, 2004; RAYWARD, 1997), a preocupação com o processo informacional já existia bem antes do fenômeno da explosão informacional.

Para os que remontam o início da disciplina aos meados do século XIX, tem-se como marco o início dos estudos sobre os métodos para o tratamento informacional. Assim, têm-se o sistema de classificação decimal de Mevil Dewey e o movimento de documentação de Paul Otlet e Henri La Fontaine, datados de 1876 e 1890 respectivamente.

Considerado o pai da documentação, Otlet, juntamente com La Fontaine, estudou em detalhes as tecnologias e os serviços bibliográficos disponíveis à sua época, o que resultou, conforme Rayward (1997), no aumento da cooperação e padronização na preparação de publicações bibliográficas. Otlet entendia que as informações extraídas do conteúdo de um livro, de seu autor e de sua intenção autoral, poderiam ser acumuladas em fichas e essas fichas agrupadas de maneira a refletir as afinidades envolvidas em cada assunto (RAYWARD, 1997). Segundo Freire (2006, p.10), Otlet acreditava que a ação de recuperar uma informação era capaz de operar a "comunicação intelectual, mudança social e paz mundial", esperando que o acesso à informação "viesse a formar uma nova opinião pública internacional e democrática, recomendando, para a preparação dessa opinião, uma organização mundial da informação".

Anteposto a isso, Rayward (1997) entende que o campo científico que viria a ser a Ciência da Informação já estava presente nas ideias de Otlet, uma vez que, ao conceituar a documentação, ele sugeria uma nova disciplina intelectual à qual associa a uma série de práticas novas e técnicas específicas. Outra vertente aponta a gênese da Ciência da Informação na biblioteconomia. Seguindo essa linha, Freire e Silva e Hayashi (2012) argumentam que, quando a biblioteca pública ganha o status de instituição socializadora e de acesso ao público, cria-se uma marca identitária do que viria ser a Ciência da Informação, uma vez que, com a alfabetização dos cidadãos, havia a necessidade de técnicas organizacionais e de difusão da informação contida nos acervos bibliográficos. Nesse contexto, Souza (2015) defende que a Ciência da Informação se configura como ambiente de aprofundamento e atualização de alguns estudos e práticas bibliotecárias. No entanto, acrescenta-se que as perspectivas da Ciência da Informação também incorporam outras áreas como a documentação, arquivologia, museologia e gestão da informação. 
Um discurso que se materializa no percurso diferente do embate entre a documentação e a biblioteconomia é de que a Ciência da Informação surgiu durante a Segunda Guerra Mundial, com uma imensa influência de cientistas norte-americanos. Esse quarto discurso pode ser remetido a Saracevic (1996) e a Barreto (2002), que dizem que o marco inicial dessa nova disciplina foi a publicação do artigo As we may think, de Vannevar Bush, em 1945, no qual o autor apontou os entraves existentes para organizar e repassar à sociedade as informações sigilosas durante a Segunda Guerra Mundial.

Após essa breve exposição historiográfica acerca das gêneses da Ciência da Informação, cabe a enumeração de alguns marcos históricos ligados diretamente a essa ciência. Álvares e Araújo Júnior (2010) fazem um trajeto histórico da Ciência da Informação, cujos primeiros indícios na direção dos estudos da informação na sociedade são encontrados em meados dos $\operatorname{anos} 1970$.

No Brasil, a narrativa historiográfica da Ciência da Informação já estava intrinsecamente ligada à documentação quando foi criado, em 1954, o Instituto Brasileiro de Bibliografia e Documentação - IBBD. No entanto, foi a biblioteconomia, segundo Nunes (2009), que teve um novo período no que se refere ao tratamento documentário através do IBBD.

Diante do exposto, o surgimento da Ciência da Informação pode ser considerado pela soma de fatores/eventos que vêm se configurando na sociedade desde o final do século XIX; eventos esses que trazem em sua essência princípios inerentes à configuração do campo disciplinar dessa ciência. Sendo assim, a gênese da Ciência da Informação pode ser encontrada nos objetivos de armazenagem e disposições das informações produzidas por todo mundo, nos adventos da explosão informacional, nos debates entre as áreas da documentação/bibliografia, da recuperação da informação e da biblioteconomia.

\subsection{A EPISTEMOLOGIA DA CIÊNCIA DA INFORMAÇÃO}

No campo científico, a discussão sobre a classificação das áreas que "são ciências" ou "não são ciências" demandou, e ainda demanda, um dispêndio de energia social muito forte. Isso porque quem detiver o controle dos discursos científicos poderá fixar as regras do jogo, como apontou Foucault (1999, p. 36): “A disciplina é um princípio de controle da produção do discurso. Ela lhe fixa os limites pelo jogo de uma identidade que tem a forma de uma reutilização permanente das regras". Desse modo, as ciências monopolizam o discurso que lhes pertence para estabelecer o que é dito e, assim, o que deve ser aprovado pelos pares. 
A disciplina científica é um domínio de objetos e, segundo Foucault (1999, p. 31), para que ela exista é necessário que exista a possibilidade de formulação indefinida de proposições novas, pois "uma disciplina não é a soma de tudo o que pode ser dito de verdadeiro sobre alguma coisa; não é nem mesmo o conjunto de tudo o que pode ser aceito, a propósito de um mesmo dado, em virtude de um princípio de coerência ou de sistematicidade". Logo, no conflito entre as disciplinas biblioteconomia e documentação/bibliografia, há uma disputa pelo controle da produção do discurso científico. No interior dessas disciplinas há o reconhecimento de proposições verdadeiras e falsas, mas cada uma delas pode, teratologicamente, retirar de seus escopos o discurso que inviabilize suas hegemonias.

Assim se comportaram as ciências naturais, detendo o poder dos discursos científicos e estabelecendo os critérios para classificar uma área de domínio científico, conforme um modelo engessado positivista no qual uma ação, para caracterizar-se como ciência, deveria ter uma justificação, método, metodologia, epistemologia, ontologia e filosofia, como foi explicitado por Rendón Rojas (2008).

As ciências humanas e sociais travaram uma luta para receber o status ciência, localizando seus objetos fenomenológicos dentro de cada subárea desse esquema modelado. As duas grandes áreas têm como objeto de estudo a realidade humana, evitando, como aponta Rendón Rojas (2008), a mera descrição e atenção de converter o sujeito em objeto, proporcionando também a justificação de seu conhecimento com uma metodologia que fundamenta a verdade de seus enunciados.

Retomando Foucault (1999), cada época tem suas instituições às quais são dadas a hegemonia e que são responsáveis pela disseminação discursiva em prol do que consideram certo e compatível com seus interesses. Nesse sentido, o filósofo francês indaga quem são as instituições que decretam o que é ciência e quem pode falar em nome dela. Logo, ao se inserir no contexto de qualquer ciência, não somente na Ciência da Informação, os cientistas que estão vinculados a instituições hegemônicas, que por sua vez disseminam discursos em prol do que consideram verdadeiro, têm o acesso à publicação de seus textos (carregados de discursos) nos meios que institucionalizam o poder, tais como os meios de distribuição da informação revistas, eventos, etc.

Segundo Bourdieu (1983), no campo científico se trava a luta pelo monopólio da competência científica, o que pode ser remetido ao domínio do discurso da área. Para Bourdieu (1983), os dominantes são os que conseguem impor uma definição da ciência e, dessa forma, exercem o poder sobre os discursos dos outros. 
O campo científico é sempre o lugar de uma luta, mais ou menos desigual, entre agentes desigualmente dotados de capital específico e, portanto, desigualmente capazes de se apropriarem do produto do trabalho científico que o conjunto dos concorrentes produz pela sua colaboração objetiva ao colocarem em ação o conjunto dos meios de produção científica disponíveis. Em todo campo se põem, com forças mais ou menos desiguais segundo a estrutura da distribuição do capital no campo (grau de homogeneidade), os dominantes, ocupando as posições mais altas na estrutura de distribuição de capital científico (BOURDIEU, 1983, p. 136).

Isso posto, entende-se que a ciência é um campo de trabalho social onde se torna mais evidente essa luta pelo domínio do discurso do outro, pois também estão envolvidas as questões políticas em que as ideologias a serem seguidas devem estar materializadas no discurso dos cientistas ditos influentes (dominantes), que constituem a ordem, as regras; isso não as impede de serem quebradas e refeitas, dependendo sempre do contexto que envolve os sujeitos sociais.

Como em qualquer outra área do conhecimento, as relações de poder na Ciência da Informação são instituídas pelas organizações e organismos que fomentam a produção, a distribuição e o consumo dos conhecimentos produzidos na área. Os cientistas da informação não ficaram indiferentes às evoluções conceituais observadas nas ciências, principalmente nas ciências sociais e humanistas no século $\mathrm{XX}$, tendo em seu campo de atuação o surgimento de várias problemáticas possibilitadas pelo mundo da tecnologia digital. Novos termos nasceram e com eles novos problemas conceituais, além de disputa entre as ciências pelo uso de tais termos.

Talvez a epistemologia não dê conta de trabalhar essa relação de poder nos discursos da Ciência da Informação; contudo, qualquer percepção filosófica deve trabalhar a convergência entre os domínios que fundamentam a Ciência da Informação, abarcando as facetas do fenômeno informacional e o espectro acerca dos conceitos, teorias e metodologias.

\section{TECNOLOGIAS INTELECTUAIS, PARADIGMAS E INDÍCIOS}

A seguir, serão apresentadas as guias do processo de busca e análise dos indícios, descrevendo os princípios do método indiciário de Ginzburg e a técnica do "brauseio" de Araújo, o percurso metodológico e as fontes de informação utilizadas, como os anais do GT-1 dos Enancib, a Brapci e a Plataforma Lattes.

\subsection{BUSCANDO OS INDÍCIOS}

Diante da combinação dos elementos teóricos com os objetos dessa pesquisa, sentiu-se a necessidade de fazer uma pesquisa sem um método fechado, algo que não deixasse o 
pesquisador engessado no próprio método. Dessa forma, optou-se pelo método do paradigma indiciário de Ginzburg (1989) que, no âmbito da Ciência da Informação, já foi usado em vários trabalhos pela pesquisadora Isa Maria Freire.

Alinhado a essa perspectiva metodológica, usou-se a técnica do "brauseio" (browsing), definida por Araújo (1994, p. 189) como "a arte de não se saber o que se quer até que se o encontre" e que, nas palavras de Freire (2014), é uma atividade de busca, tendo como causa uma necessidade ou interesse de informação percebido.

O método do paradigma indiciário, apresentado por Ginzburg (1989), consiste num conjunto de princípios que atenta para os detalhes, dados marginais, resíduos, pistas, indícios, sinais, vestígios. Em uma linguagem metafórica, é o percurso em que se pode tomar em um tecido, seguindo fio a fio, de modo a se fazer a investigação. Nas palavras de Ginzburg (1989, p. 170), "Trata-se [de remeter, a partir] de adjetivos não-sinônimos, [...] a um modelo epistemológico comum, articulado em disciplinas diferentes, muitas vezes ligadas entre si pelo empréstimo de métodos ou termos-chave". A escolha desse método se deu pelo fato do autor da presente pesquisa não acreditar que a Ciência da Informação se encaixe na perspectiva da ciência tradicional estabelecida pela percepção positivista. Sendo assim, o método indiciário permite colocar a referida ciência no

[...] grupo de disciplinas que chamamos de indiciárias [e que] não entra absolutamente nos critérios de cientificidade deduzíveis do paradigma galileano. Trata-se, de fato, de disciplinas eminentemente qualitativas, que têm por objeto casos, situações e documentos individuais, enquanto individuais (GINZBURG, 1989, p. 156).

O paradigma indiciário de Ginzburg (1989) é considerado um método interpretativo, no qual o pesquisador é analogeticamente o caçador que atenta para os vestígios de sua caça (as pegadas, fezes, pelos) para criar a narrativa das causas e efeitos da passagem da caça. Para o filósofo, é necessário examinar os pormenores mais negligenciáveis e menos influenciados pela instituição a qual pertença o artista/pesquisador/caçador.

O outro método usado no sistema de busca foi "brauseio" que, segundo Araújo (1994), é uma estratégia que consiste em andar a esmo, ou deambular, colhendo flashes de qualquer tipo de informação. Para Naves (1998), "brauseio" consiste numa atividade não orientada, não sistemática, casual, informal, não programada. Sendo assim, o termo é definido como uma busca que não necessita de critérios e objetivos pré-estabelecidos.

A forma de pesquisa pelo "brauseio", segundo Araújo (1994), se dá por um processo de exploração visual, por meio do "acesso direto" sem ajuda de um mediador. Dessa forma, é o encontrar por acaso o que lhe interessa, ou seja, "outra forma de descrever o processo de 
brausear seria equivalê-lo à 'arte de não saber o que se quer até que se o encontre" (ARAÚJO, 1994, p. 108).

Na perspectiva de Freire (2014), "brauseio" é uma atividade de busca derivada de uma necessidade ou interesse informacional percebido, o que no âmbito desta pesquisa consiste em buscar pistas sobre as relações de colaboração na produção e comunicação de artigos que tratam da historiografia e epistemologia da Ciência da Informação, publicados nos anais do GT-1 e na Brapci. Nessa mesma perspectiva, Hassan-Montero (2006) argumenta que o processo de "brauseio" se dá quando o usuário explora visual e espacialmente o conjunto de documentos, sem ter a necessidade de expressar previamente quais são suas necessidades informacionais em outras palavras, sem especificar suas necessidades mediante a linguagem de consulta.

\subsection{PERCURSO METODOLÓGICO}

O percurso metodológico da pesquisa consiste em valorizar as especificidades e as regularidades da produção e comunicação científica da epistemologia da Ciência da Informação, reconhecendo as formas com que essa área produz o conhecimento. Também se caminha para inferir as causas comportamentais da literatura da área a partir dos efeitos que compõem as relações interpessoais dos pesquisadores. Assim, há um exercício criativo de conjecturas e inferências durante a busca pelos indícios e análise dos sinais observados. Ainda dentro da perspectiva do paradigma indiciário, faz-se uma análise bibliométrica e cientométrica dos detalhes acerca da epistemologia e historiografia da Ciência da Informação, utilizando um pluralismo documental, teórico e metodológico.

Esta pesquisa se encaixa na categoria descritiva, pois permite descrever as características da produção e comunicação científica acerca da epistemologia e historiografia da Ciência da Informação a partir da verificação descritiva de um fenômeno. Assim, a produção científica da temática aqui mencionada é analisada a partir da identificação do coletivo de pesquisadores, relações instituídas entre eles e os elementos que compõem a estrutura dessa produção científica, evidenciando também as relações de poder institucionalizadas na área.

Para a forma da abordagem, o estudo é caracterizado pelos métodos de análise quantitativa e qualitativa. A análise quantitativa se dá na coleta de dados para a aplicação das perspectivas dos estudos métricos da informação como a bibliometria, informetria e a cientometria, pelas quais obter-se-ão alguns principais indicadores de modo genérico expressos por Noronha e Maricato (2008, p. 123), a saber: “evolução quantitativa e qualitativa da literatura", "dinâmica e estrutura da comunicação científica (principalmente formal)", "ranking 
de publicações, autores, instituições", "estudos de citação" e "estudos de colaboração científica (principalmente baseados em coautoria)". O enfoque passa a ser qualitativo quando se faz a interpretação desses resultados quantitativos por meio de análise reflexiva que estabeleça a relação das variáveis, observando o contexto das "condições sociais, institucionais e ambientais em que as vidas das pessoas se desenrolam" (YIN, 2016, p. 7).

Em relação aos procedimentos de coleta de dados, esta pesquisa se caracteriza como um estudo de caso, pois, como define Fonseca (2002, p. 33),

\begin{abstract}
Um estudo de caso pode ser caracterizado como um estudo de uma entidade bem definida como um programa, uma instituição, um sistema educativo, uma pessoa, ou uma unidade social. [...] O estudo de caso pode decorrer de acordo com uma perspectiva interpretativa, que procura compreender como é o mundo do ponto de vista dos participantes, ou uma perspectiva pragmática, que visa simplesmente apresentar uma perspectiva global, tanto quanto possível completa e coerente, do objeto de estudo do ponto de vista do investigador.
\end{abstract}

Na perspectiva de Gil (2002), com relação à coleta de dados, o estudo de caso é o mais completo porque se vale dos dados em relação à pessoa e dados documentais. Destarte, esta pesquisa restringe sua investigação aos pesquisadores que publicaram trabalhos nos anais do GT-1 dos Enancib no recorte temporal de 2003 a 2018 e autores de artigos de periódicos indexados na Brapci no mesmo recorte temporal.

Diante do exposto, o percurso percorrido na pesquisa consistiu no levantamento de dados a partir do portal de eventos da Ancib, do qual são retirados dados referentes ao GT-1 para, desse modo, formar um banco de dados tabulado no software Excel versão 14.5.0. Especificamente, os dados retirados dos anais dos Enancib foram publicados de 2003 a 2018. Para essa etapa, também se fez a busca na Brapci por artigos que tratem da epistemologia e/ou historiografia da Ciência da Informação. O desenvolvimento do trabalho se deu pela mensuração dos dados, confecção de gráficos e tabelas para análise.

Vale ressaltar que havia a dificuldade de muitos dados necessários à pesquisa não serem encontrados nos documentos indexados no Portal da Ancib e na Brapci, que pôde ser superada mediante buscas em outros portais da área e no currículo Lattes dos pesquisadores. Num primeiro momento, houve problemas com a Brapci, que foram solucionados com disponibilização de uma nova plataforma por parte da equipe da referida base.

Sendo assim, a análise da produção científica da temática epistemologia e historiografia da Ciência da Informação se deu pelas seguintes etapas: (a) identificação dos autores que mais produziram sobre a temática "Epistemologia da Ciência da Informação", no Brasil; (b) estabelecimento das relações que conectam os autores entre si, instituições de vínculos dos pesquisadores da temática. A pesquisa busca, no território da literatura científica: 
- os autores, suas ligações institucionais e atributos no campo científico;

- a rede de coautorias por tipo de colaboração (pesquisa, orientação e outros).

Outras atividades foram desenvolvidas simultaneamente à caça aos indícios, ou $a$ posteriori a essa ação: aplicações de estudos métricos como os bibliométricos, cientométricos e informétricos; regime de colaboração entre os pesquisadores do núcleo duro de pesquisadores do campo de pesquisa; construção da narrativa/análise a partir das pistas encontradas.

\subsection{FONTES DE INFORMAÇÃO}

Trazemos, aqui, a descrição do universo da pesquisa, ou seja, o espaço onde está inserida a população a ser investigada: o núcleo de pesquisadores mais produtivos no contexto da temática epistemologia e historiografia da Ciência da Informação. Desta forma, esses ambientes são considerados o cenário natural do qual se obtiveram as pistas, indícios, detalhes de como a produção e comunicação científica acontecem e as relações estabelecidas entre os pesquisadores da referida temática.

\subsubsection{Breve história do GT-1 no Enancib}

Vários domínios do conhecimento estabelecem espécies de grupos de trabalho e fóruns que permitem debates e reflexões com intuito de promover o progresso das pesquisas e dos trabalhos científicos, tecnológicos e sociais. Com esse mesmo objetivo, os pesquisadores da Ciência da Informação, por meio da Associação Nacional de Pesquisa e Pós-Graduação em Ciência da Informação (Ancib), estabeleceram o Encontro Nacional de Pesquisa em Ciência da Informação (Enancib), realizado desde 1994.

O Enancib, por meio dos grupos de trabalho da Ancib, é uma das mais importantes vitrines que permitem a visualização das pesquisas que vêm sendo desenvolvidas especialmente nos cursos de pós-graduação em Ciência da Informação acerca das questões epistemológicas e históricas dessa área. Atualmente, a Ancib se organiza 11 grupos de trabalho, sendo cada um responsável por uma temática de pesquisa:

- GT-01 - Estudos Históricos e Epistemológicos da Informação;

- GT-02 - Organização e Representação do Conhecimento;

- GT-03 - Mediação, Circulação e Apropriação da Informação;

- GT-04 - Gestão da Informação do Conhecimento;

- GT-05 - Política e Economia da Informação; 
- GT-06 - Informação, Educação e Trabalho;

- GT-07 - Produção e Comunicação da Informação em Ciência, Tecnologia \& Inovação;

- GT-08 - Informação e Tecnologia;

- GT-09 - Museu, Patrimônio e Informação;

- GT-10 - Informação e Memória;

- GT-11 - Informação e Saúde.

Com apoio dos programas de ciência da informação, a Ancib promove anualmente o Enancib, evento no qual são levados a fórum resultados e reflexões acerca das pesquisas desenvolvidas na área. Já aconteceram 19 edições (1994 a 2018) do Enancib, conforme Quadro 1:

Quadro 1 - As Edições do Enancib (1994-2018)

\begin{tabular}{|ccl|}
\hline ENANCIB & ANO & \multicolumn{1}{c|}{ LOCAL } \\
I & 1994 & Belo Horizonte - MG \\
II & 1995 & Valinhos - SP \\
III & 1997 & Rio de Janeiro - RJ \\
IV & 2000 & Brasília - DF \\
V & 2003 & Belo Horizonte - MG \\
VI & 2005 & Florianópolis - SC \\
VII & 2006 & Marília - SP \\
VIII & 2007 & Salvador - BA \\
IX & 2008 & São Paulo - SP \\
X & 2009 & João Pessoa - PB \\
XI & 2010 & Rio de Janeiro - RJ \\
XII & 2011 & Brasília - DF \\
XIII & 2012 & Rio de Janeiro - RJ \\
XIV & 2013 & Florianópolis - SC \\
XV & 2014 & Belo Horizonte - MG \\
XVI & 2015 & João Pessoa - PB \\
XVII & 2016 & Salvador - BA \\
XVIII & 2017 & Marília - SP \\
XIX & 2018 & Londrina - PR \\
\hline
\end{tabular}

Fonte: Dados da pesquisa, 2018.

A ementa atual do GT-1 é "Estudos históricos e epistemológicos da Ciência da Informação. Constituição do campo científico e questões epistemológicas e históricas da Ciência da Informação e seu objeto de estudo - a informação. Reflexões e discussões sobre a 
disciplinaridade, interdisciplinaridade e transdisciplinaridade, assim como a construção do conhecimento na área”.

\subsubsection{A Brapci - Base de Dados Referenciais de Artigos de Periódicos em Ciência da informação}

A Base de Dados Referenciais de Artigos de Periódicos em Ciência da informação (Brapci) é uma importante ferramenta de pesquisa na área da Ciência da Informação. Essa base de dados compõe hoje um conjunto de instrumentos que vão de um simples "brauseio" pelos artigos da área até a sua utilização como recurso metodológico de investigação de temáticas.

Segundo Gabriel Júnior (2014), a idealização da Brapci se deu na concepção de estudo pós-doutoral da professora Leilah Santiago Bufrem no ano de 1995, tendo como intuito o desenvolvimento de um repertório representativo da produção científica do Brasil e da Espanha. Depois de várias experiências, o projeto tomou uma dimensão muito grande, o que o deixa no patamar de várias outras bases como Scielo, Google Scholar, Scopus, entre outras.

Segundo a própria Brapci, no início de 2019 o seu corpus consistia na composição de 57 periódicos, 19.255 trabalhos publicados em revistas científicas, 2.481 pesquisas publicados em anais de eventos da área, 16.214 autores, 2 livros e 1 tese. Sua cobertura temporal se inicia em 1972, podendo ser recuperados trabalhos por meio de termos de busca nos campos: autores, título, palavras-chave, resumo e referências. Isso sem contar com a atualização dos dados para os anos de 2019 e 2020 (ainda em curso).

\section{4 “O CIENTISTA É UM CAÇADOR DO INVISÍVEL"3}

Diferentemente dos que seguem a perspectiva de que o cientista trabalha com fatos, com aquilo que pode ser visto, tocado e medido, colocando em oposição ao senso comum, segue-se aqui a tese de Alves (1981), na qual o cientista é caçador do invisível, como aponta o autor: “A ciência se inicia com problemas. Um problema significa que há algo errado ou não resolvido com os fatos. O seu objetivo é descobrir uma ordem invisível que transforme os fatos de enigma em conhecimento" (ALVES, 1981, p. 31). Dessa forma, o autor argumenta que o processo de investigação científica não se conclui com os registros de seus dados, mas seu início se dá com eles. Subsequentemente, o produto científico final é uma teoria ou hipótese de trabalho, não sendo o que se chama de "fato".

\footnotetext{
${ }^{3}$ Rubem Alves, no livro "Filosofia da ciência: introdução ao jogo e suas regras", 1981, p.31.
} 
Nesse sentido, a pesquisa que se apresenta a seguir permitiu coletar indícios da produção literária de um determinado grupo de pesquisadores acerca da temática epistemologia e historiografia da Ciência da Informação. Para tanto, vale lembrar que a busca se deu por meio do método dos indícios (GINZBURG, 1989) e da técnica de "brauseio"/browsing (ARAÚJO, 1994), buscando pistas, indícios, detalhes, vestígios, entre outros, que permitiram inferir as circunstâncias para o desenvolvimento das discussões do tema proposto nessa pesquisa. Em outras palavras, fez-se a investigação para perceber como os fios da produção científica dos pesquisadores se entrelaçam na confecção do tecido epistemológico e historiográfico da Ciência da Informação.

Para a coleta dos dados, o recorte temporal se deu, para os anais do Enancib, no intervalo de 2003 a 2018, onde buscou-se que pesquisadores mais publicaram no GT-1, assim como nos periódicos indexados na Brapci, e quais desses mantêm certa regularidade de participação nessas publicações e as instituições que mais se evidenciam na representação de seus pesquisadores. Portanto, atende-se ao objetivo de identificar o coletivo de pesquisadores que dão suporte, continuidade e consistência ao trabalho epistemológico e historiográfico da Ciência da Informação, assim como de investigar o contexto do seu desenvolvimento a partir das comunicações científicas dos estudiosos da área.

\subsection{A BUSCA NOS ANAIS DOS ENANCIB}

Desde 2003, o GT-1 apresenta uma variação na quantidade de comunicações de pesquisas, com reflexo na sua publicação nos anais, como pode ser observado na Tabela 1.

Tabela 1 - Enancib Trabalhos comunicados e publicados (2003-2018).

\begin{tabular}{c|c|c|c}
\hline Ano & Local do Enancib & Frequência & Representação \\
\hline 2003 & Belo Horizonte - MG & 15 & $0,00 \%$ \\
\hline 2005 & Florianópolis - SC & 16 & $6,25 \%$ \\
\hline 2006 & Marília - SP & 14 & $-14,29 \%$ \\
\hline 2007 & Salvador - BA & 20 & $30,00 \%$ \\
\hline 2008 & São Paulo - SP & 21 & $4,76 \%$ \\
\hline 2009 & João Pessoa - PB & 17 & $-23,53 \%$ \\
\hline 2010 & Rio de Janeiro - RJ & 20 & $15,00 \%$ \\
\hline 2011 & Brasília - DF & 23 & $13,04 \%$ \\
\hline 2012 & Rio de Janeiro - RJ & 28 & $17,86 \%$ \\
\hline 2013 & Florianópolis - SC & 25 & $-12,00 \%$ \\
\hline 2014 & Belo Horizonte - MG & 20 & $-25,00 \%$ \\
\hline
\end{tabular}




\begin{tabular}{c|c|c|c}
\hline 2015 & João Pessoa - PB & 18 & $-11,11 \%$ \\
\hline 2016 & Salvador - BA & 29 & $37,93 \%$ \\
\hline 2017 & Marília - SP & 33 & $12,12 \%$ \\
\hline 2018 & Londrina - PR & 29 & $-13,79$ \\
\hline Total & & $\mathbf{3 2 8}$ & \\
\hline
\end{tabular}

Fonte: Dados da pesquisa, 2018.

Nesse contexto, as publicações se mantiveram a partir de 20 ocorrências em 2007, 2008, 2010 a 2014, tendo um pequeno decréscimo em 2015, voltando a subir em 2016. Percebe-se que o pico de publicações aconteceu em 2017, no Enancib de Marília, com o total de 33 publicações, equivalendo a $10 \%$ do total de todas as publicações nos últimos 16 anos. Vale ressaltar que o Enancib de Salvador, em 2016, e o de Londrina, em 2018, com 29 publicações cada, representam juntos $18 \%$ do total de todas as publicações no referido GT.

\subsubsection{Instituições no GT-1}

As instituições com programas de pós-graduação na área que mais se destacam em publicações no GT-1 estão concentradas na região Sudeste, com quatro instituições do Rio de Janeiro (Instituto Brasileiro de Informação em Ciência e Tecnologia - Ibict; Universidade Federal do Rio de Janeiro - UFRJ; Universidade Federal do Estado do Rio de Janeiro - Unirio; e Universidade Federal Fluminense - UFF); uma de Minas Gerais (Universidade Federal de Minas Gerais); e duas de São Paulo (Universidade de São Paulo - USP e Universidade Estadual Paulista - Unesp). Nessa região, nos estados do Rio de Janeiro, São Paulo e Minas Gerais, surgiram os cursos de doutorado em ciência da informação, evento que se pode tomar como referência histórica para entender o domínio da referida região na produção da temática.

A região Centro-Oeste está representada pela Universidade de Brasília (UnB), enquanto a região Sul se representa por meio da Universidade Federal de Santa Catarina (UFSC) e da Universidade Federal do Rio Grande do Sul (UFRGS). O Nordeste está representado pela já mencionada Universidade Federal da Paraíba (UFPB), pela Universidade Federal da Bahia (UFBA), pela Universidade Federal de Alagoas (Ufal), além da Universidade Federal do Cariri (UFCA) e da Universidade Federal de Pernambuco (UFPE). 
Gráfico 1 - Representação das instituições.

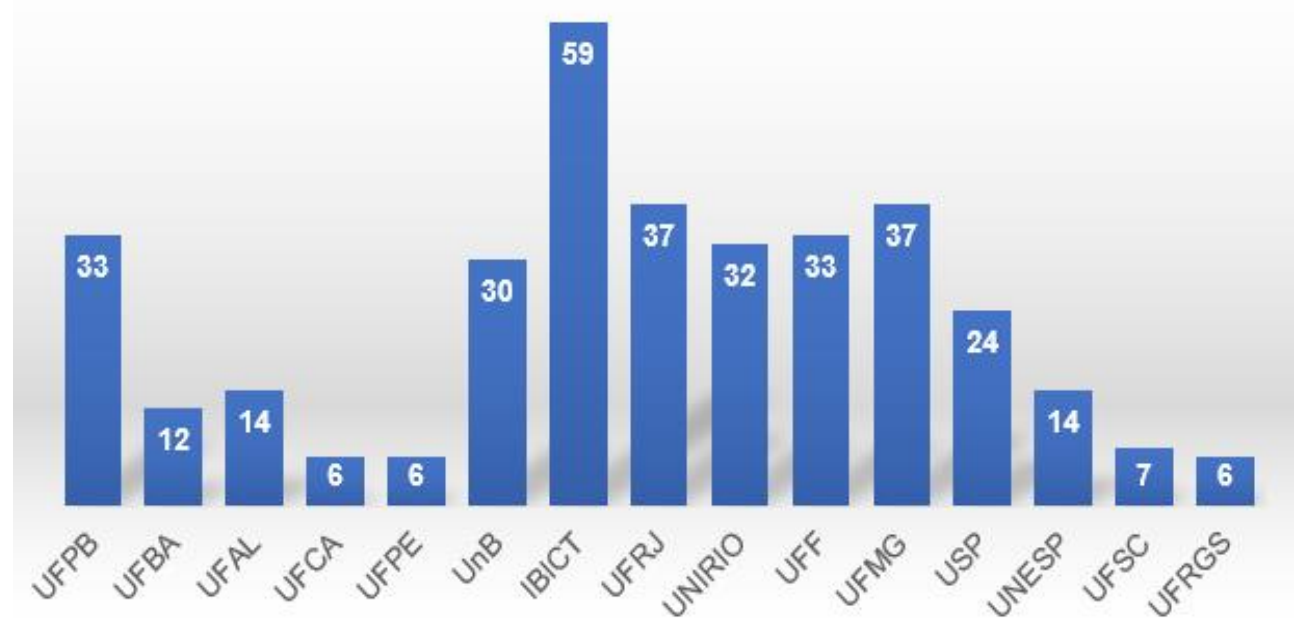

Fonte: Dados da pesquisa, 2018.

Faz-se menção à participação de pesquisadores de dois museus - Museu de Astronomia e Ciências Afins (Mast) e Museu da República -, de secretarias e de órgãos de governo, da Câmara Federal, além de participação das instituições privadas de ensino e outros centros públicos de pesquisa, como a Fundação Oswaldo Cruz (Fiocruz). Identifica-se, no levantamento de dados sobre o GT-1, a participação de 45 instituições de diferentes segmentos.

Outros dados merecem destaque, como a participação, em 2012, 2013, 2016 e 2017, de cinco instituições internacionais: a University of Baltimore (Estados Unidos), a Universidad del Zulia (Venezuela), a Universidad de la Salle (Colômbia), a Universidade do Porto (Portugal) e a Universidad de Granada (Espanha). Esses dados demonstram o grau de contribuição do GT1, no âmbito do Enancib, para o processo de internacionalização da Ciência da Informação brasileira.

\subsubsection{Os autores do GT-1}

Em relação ao número de pesquisadores que apresentaram suas comunicações, identificam-se 312 pesquisadores da Ciência da informação que participaram do GT-1, ao longo do período, podendo-se inferir, a priori, a existência de um espaço democrático onde os pesquisadores podem comunicar e debater suas pesquisas.

Observou-se que número significativo dos trabalhos sobre epistemologia e historiografia da Ciência da Informação é produzido regularmente por um pequeno número de autores, e mesmo que esses produtores juntos ultrapassem a quantidade de trabalhos publicados 
pelos demais pesquisadores (os que têm poucas pesquisas publicadas nos anais do GT-1 no Enancib), a maioria apresentou apenas uma produção no período. Assim, pode-se registrar a validação da primeira hipótese desta tese, que se configura como afirmação de que os indícios de produção científica acerca da temática em tela remetem a um pequeno grupo de pesquisadores que mantêm regularidade de publicações.

Levando em consideração apenas os pesquisadores que publicaram quatro trabalhos ou mais, têm-se apenas $10 \%$ dos pesquisadores publicando com certo grau de regularidade, no período; sendo que 4,5\% de pesquisadores publicaram três trabalhos; outros 13,5\% publicaram duas vezes; e $72 \%$ publicaram apenas uma vez, evidenciando a alta rotatividade de pesquisadores que apresentaram comunicações no GT-1.

Questões acerca dessa rotatividade surgem direcionadas a refletir o porquê de tantos indivíduos fazerem uma única contribuição e o porquê de relações serem estabelecidas entre os pesquisadores do referido grupo. Essas indagações puderam ser confrontadas com os resultados da caçada feita na plataforma Brapci.

\subsection{A BUSCA NA BRAPCI}

Foi necessário descartar a primeira busca feita na Brapci, uma vez que a antiga plataforma apresentava inconsistência de dados, repetindo os artigos diversas vezes, replicando-os em inglês. Houve determinados momentos em que as caixas de filtro da referida plataforma não funcionavam. No entanto, em 2018, num trabalho conjunto entre a Universidade Federal do Paraná e a Universidade Federal do Rio Grande do Sul, foi disponibilizada uma reestruturação técnica, visual e funcional da plataforma supracitada, agora nomeada Brapci Beta 4.0, utilizando o ElasticSearch como mecanismo de busca.

Buscou-se, na plataforma, artigos pelos descritores "epistemologia da ciência da informação", "historiografia da ciência da informação" e "filosofia da informação", optando pela reunião desses descritores em todos os campos de metadados encontrados (autores, títulos, palavras-chave, resumo e referências). O recorte temporal foi o período de 2003 a 2018, aplicando-se o mesmo recorte dos anais do Enancib. Ressalta-se que essa técnica, a princípio, excluiu alguns autores de grande relevância para área, uma vez que os metadados de seus artigos não correspondiam ao mecanismo de busca automática; contudo, recuperou-se dados significantes para o entendimento da crescente produção na temática por parte de pesquisadores relativamente novos no contexto de discussão da epistemologia e historiografia da área. 
Restringiu-se os trabalhos a artigos que tivessem pesquisadores brasileiros e que apenas tratassem da epistemologia/filosofia e historiografia da Ciência da Informação, biblioteconomia, documentação, arquivologia e seus derivados. Sendo assim, quando se buscou pelo termo "epistemologia da Ciência da Informação", obteve-se 144 resultados, mas, após o filtro manual, restaram 107 artigos. Na busca pelo termo "historiografia da Ciência da Informação" foram recuperados 16 artigos; contudo, depois da exclusão dos que já haviam sido recuperados pelo termo "epistemologia da Ciência da Informação" e de historiografias que não tinham relação direta com a Ciência da Informação, biblioteconomia, documentação, arquivologia e seus derivados, restaram apenas quatro artigos.

Com o termo "filosofia da Ciência da Informação", foram recuperados 134 artigos, mas após filtro pelo qual se retirou os artigos já recuperados por meio dos outros termos, além dos escritos exclusivamente por autores estrangeiros e ligados unicamente a instituição não brasileira, ficaram 66 artigos. Dessa forma, os dados para análise das publicações nos periódicos indexados na Brapci Beta 4.0 foram levantados em 177 artigos científicos.

O Quadro 2 apresenta uma timeline de criação de 42 periódicos indexados na Brapci, no período de 2003 a 2018.

Quadro 2 - Timeline (2003-2018) de criação de periódicos indexados na Brapci.

\begin{tabular}{|l|l|}
\hline Ano & \multicolumn{1}{|c|}{ Periódico } \\
\hline 2003 & Em Questão \\
\hline 2003 & Infociência \\
\hline 2003 & $\begin{array}{l}\text { Revista Digital de Biblioteconomia \& Ciência da } \\
\text { informação }\end{array}$ \\
\hline 2004 & Revista Alexandria (Peru) \\
\hline 2005 & Arquivística.net \\
\hline 2005 & Biblionline \\
\hline 2005 & Liinc em revista \\
\hline 2005 & Prisma.com (Portugual) \\
\hline 2006 & Brazilian Journal of Information Science \\
\hline 2006 & $\begin{array}{l}\text { Pesquisa Brasileira em Ciência da informação e } \\
\text { Biblioteconomia }\end{array}$ \\
\hline 2007 & Ponto de Acesso \\
\hline 2008 & CRB8 Digital \\
\hline 2008 & Revista Ibero-Americana de Ciência da informação \\
\hline 2008 & $\begin{array}{l}\text { Tendências da Pesquisa Brasileira em Ciência da } \\
\text { informação }\end{array}$ \\
\hline 2010 & $\begin{array}{l}\text { InCID: Revista de Ciência da informação e } \\
\text { Documentação }\end{array}$ \\
\hline
\end{tabular}




\begin{tabular}{|c|c|}
\hline 2010 & Inclusão Social \\
\hline 2011 & AtoZ: Novas Práticas em Informação e Conhecimento \\
\hline 2011 & $\begin{array}{l}\text { Bibliotecas Universitárias: pesquisas, experiências e } \\
\text { perspectivas }\end{array}$ \\
\hline 2011 & e-Ciencias de la Información (Costa Rica) \\
\hline 2011 & Múltiplos Olhares em Ciência da informação \\
\hline 2011 & Palabra Clave (Argentina) \\
\hline 2011 & Perspectivas em Gestão \& Conhecimento \\
\hline 2012 & Biblioteca Escolar em Revista \\
\hline 2012 & Huellas en papel (Argentina) \\
\hline 2012 & Informação Arquivística \\
\hline 2012 & Informação@Profissões \\
\hline 2012 & IRIS - Revista de Informação, Memória e Tecnologia \\
\hline 2013 & Archeion Online \\
\hline 2013 & Revista Analisando em Ciência da informação \\
\hline 2014 & CAJUR - Caderno de Informações Juridicas \\
\hline 2014 & Ciência da informação em Revista \\
\hline 2014 & Informação \& Tecnologia \\
\hline 2014 & Logeion: Filosofia da Informação \\
\hline 2014 & Revista Brasileira de Educação em Ciência da informação \\
\hline 2014 & Revista Informação na Sociedade Contemporânea \\
\hline 2014 & Revista P2P e INOVAÇÃO \\
\hline 2015 & Folha de Rosto \\
\hline 2016 & Informação em Pauta \\
\hline 2016 & Revista Conhecimento em Ação \\
\hline 2018 & Convergência em Ciência da informação \\
\hline 2018 & Revista Cajueiro \\
\hline 2018 & Revista Fontes Documentais \\
\hline
\end{tabular}

Fonte: Dados da pesquisa, 2018

Diante do exposto, considera-se que o aumento de periódicos no período do recorte tenha influenciado no crescimento de publicações, assim como as regularidades na periocidade de publicações dos periódicos já existentes à época. Novos programas de pós-graduação em Ciência da Informação surgiram a partir de 2010 e com eles seus periódicos institucionalizados. Também surgiram temáticas que necessitaram de periódicos especializados, assim como o número de periódicos (indexados na Brapci) em atividade é cinco vezes maior do que os que foram extintos. Existem na coleção da Brapci 76 periódicos em sua totalidade, dos quais 16 se encontram extintos, e ainda há artigos dos anais dos Enancib e dos EBBC - Encontro Brasileiro de Bibliometria e Cientometria. 
Dessa forma, o sistema de periódicos da área se confira como ambiente com perspectiva de crescimento em virtude da necessidade de abranger os programas de pós-graduação em Ciência da informação de regiões que ainda dispõem de poucos cursos, por exemplo, a região Norte.

\subsection{OS AUTORES NA BRAPCI}

A verificação dos autores mais atuantes em relação à temática epistemologia e historiografia da Ciência da Informação nos periódicos indexados na Brapci mostrou uma configuração diferente no grupo núcleo de pesquisadores em relação ao núcleo duro do GT-1. Para melhor entendimento, apresenta-se no Quadro 3 os pesquisadores com as maiores frequências de publicação de artigo acerca da temática, a partir dos termos descritores inseridos para a recuperação automática na Brapci.

Quadro 3 - Pesquisadores mais frequentes em artigos indexados na Brapci (2003-2018).

\begin{tabular}{|c|c|c|}
\hline Autoria & $\mathbf{f} / \mathbf{x}$ & Anos \\
\hline Gustavo da Silva Saldanha & 20 & $\begin{array}{l}\text { 2008, 2010, 2011, 2011, 2012, 2012, 2012, 2013, 2014, 2015, } \\
2017,2017,2018,2018,2018,2018,2018,2018,2018,2018\end{array}$ \\
\hline Solange Puntel Mostafa & 13 & $\begin{array}{l}\text { 2010, 2011, 2012, 2013, 2014, 2015, 2016, 2017, 2017, 2017, } \\
2018,2018,2018\end{array}$ \\
\hline Igor Soares Amorim & 8 & 2014, 2017, 2017, 2017, 2018, 2018, 2018, 2018 \\
\hline Carlos Alberto Ávila Araújo & 7 & 2010, 2013, 2013, 2014, 2014, 2016, 2018 \\
\hline Jonathas Luiz Carvalho Silva & 7 & 2007, 2012, 2013, 2013, 2013, 2015, 2015 \\
\hline Rodrigo Rabello & 6 & $2008,2010,2011,2013,2013,2018$ \\
\hline Henriette Ferreira Gomes & 5 & $2011,2013,2013,2015,2016$ \\
\hline Marisa Bräscher & 5 & $2011,2012,2017,2017,2018$ \\
\hline Angelica Alves da Cunha Marques & 4 & $2013,2015,2016,2017$ \\
\hline Marivalde Moacir Francelin & 4 & $2003,2004,2015,2018$ \\
\hline Clarice Fortkamp Caldin & 3 & $2016,2017,2018$ \\
\hline Elizete Vieira Vitorino & 3 & $2011,2016,2018$ \\
\hline Isa Maria Freire & 3 & $2014,2015,2018$ \\
\hline Juliana Lazzaroto de Freitas & 3 & $2010,2010,2014$ \\
\hline Leilah Santiago Bufrem & 3 & $2010,2010,2014$ \\
\hline Miriam Paula Manini & 3 & $2016,2017,2017$ \\
\hline Murilo Artur Araújo da Silveira & 3 & $2017,2017,2018$ \\
\hline Silvana Drumond Monteiro & 3 & $2006,2007,2008$ \\
\hline Sônia Elisa Caregnato & 3 & $2017,2017,2018$ \\
\hline Valéria Cristina Lopes Wilke & 3 & $2011,2012,2015$ \\
\hline William Barbosa Vianna & 3 & $2016,2017,2018$ \\
\hline
\end{tabular}

Fonte: Dados da pesquisa, 2018.

A maioria dos trabalhos recuperados nos anais do GT-1 e nos periódicos indexados na Brapci foi construída em regime de colaboração, o que será visto em seção posterior, sendo que 
muitos dos pesquisadores que apresentam poucas publicações na temática são orientandos dos pesquisadores que estão no grupo de elite ou que dele se aproximam. Isso caracteriza um ambiente mais colaborativo quando é visto de forma mais intrínseca, mas quando se observa de um ponto de vista mais holístico, considerando todos os componentes dessas relações, é perceptível a competição: quando um pesquisador se destaca dentro de um grupo capital científico lhe é outorgado e a compensação se materializa em bolsas de produtividade, bolsas de pesquisa, entre outros, uma vez que as políticas de fomento estabelecem cotas para as áreas, estimulando a competição.

\subsection{A FRENTE DE PESQUISA: GT-1 E PERIÓDICOS INDEXADOS NA BRAPCI}

A produtividade dos pesquisadores pode lhes proporcionar o capital científico, a autoridade científica, prestígio, reconhecimento e celebridade, bem como suas derivações. Esses são recursos científicos que, acumulados, aumentam a notoriedade do pesquisador e/ou de seus trabalhos. Nesse sentido, percebe-se que quanto maior a quantidade de trabalhos do pesquisador mais próximo do grupo da elite sobre determinada temática ele estará, e quando se trata das perspectivas qualitativas do seu trabalho, ele pode estar no grupo de pesquisadores que compõem o grupo de frente de pesquisa. Segundo Urbizagastegui-Alvarado (2009, p. 78), “existe alta correlação entre a qualidade e a quantidade das publicações, em razão de que o êxito na publicação renova os esforços para mais publicações", mas quando os trabalhos são rejeitados por um instrumento de comunicação científica, pode haver inibição de uma possível nova submissão de trabalhos.

A frente brasileira de pesquisa é composta por pesquisadores, muitos deles componentes do grupo elite sobre a temática, como pode ser visto na Tabela 2 para o GT-1 e artigos de periódicos indexados na Brapci.

Tabela 2 - Frente brasileira de pesquisa sobre a temática a partir do GT-1 e dos artigos indexados na Brapci.

\begin{tabular}{l|c|c|c}
\multicolumn{1}{c|}{ Autores } & $\begin{array}{c}\text { Referências } \\
\text { GT-1 }\end{array}$ & $\begin{array}{c}\text { Referências } \\
\text { Brapci }\end{array}$ & $\begin{array}{c}\text { EGT-1 e } \\
\text { Brapci }\end{array}$ \\
\hline GONZÁLEZ DE GÓMEZ, M. N. & 207 & 94 & 301 \\
\hline PINHEIRO, Lena Vania Ribeiro & 128 & 56 & 184 \\
\hline JAPIASSU, Hilton Ferreira & 57 & 35 & 92 \\
\hline ARAÚJO, Carlos Alberto Ávila & 42 & 36 & 78 \\
\hline BARRETO, Aldo de Albuquerque & 47 & 26 & 73 \\
\hline MOSTAFA, S. P. & 31 & 26 & 57 \\
\hline SMIT, Johanna W. & 36 & 20 & 56 \\
\hline FREIRE, I. M. & 38 & 13 & 51
\end{tabular}




\begin{tabular}{|c|c|c|c|}
\hline FONSECA, Maria Odila & 33 & 15 & 48 \\
\hline JARDIM, José Maria & 29 & 15 & 44 \\
\hline MARTELETO, Regina Maria & 25 & 18 & 43 \\
\hline TÁLAMO, Maria de Fátima G. M. & 25 & 17 & 42 \\
\hline LOUREIRO, José Mauro Matheus & 27 & 14 & 41 \\
\hline ORTEGA, Cristina D. & 25 & 13 & 38 \\
\hline KOBASHI, N. Y. & 21 & 16 & 37 \\
\hline LARA, M. L. G. & 15 & 18 & 33 \\
\hline OLIVEIRA, Marlene & 23 & 10 & 33 \\
\hline NOVA CRUZ, Denise V. & 10 & 21 & 31 \\
\hline ROBREDO, Jaime. & 16 & 15 & 31 \\
\hline FREIRE, Gustavo Henrique de Araújo & 15 & 13 & 28 \\
\hline SILVA, Manoel Cícero Peregrino da & 27 & - & 27 \\
\hline RABELLO, Rodrigo & 11 & 15 & 26 \\
\hline FREIRE, P. & 8 & 16 & 24 \\
\hline SALDANHA, Gustavo S. & 19 & 5 & 24 \\
\hline FREITAS, Lídia S. & 18 & - & 18 \\
\hline
\end{tabular}

Fonte: Dados da pesquisa, 2018.

No grupo que se apresenta na Tabela 2, alguns autores não fazem parte da produção acadêmica da Ciência da Informação e são referenciados na área sob a mesma perspectiva que as demais ciências o fazem, utilizando as ideias gerais desses autores para a compreensão da realidade sob o ponto de vista da Ciência da Informação.

Muitos trabalhos são publicados em coautoria oriunda de algum tipo de relação estabelecida na academia, como pesquisadores de domínios específicos e/ou distintos que se juntam para desenvolver pesquisas com objeto comum a ambos. Nesse contexto, ainda existem as relações de interesses com objetivos estritamente de colação de grau e de produtividade, como a de estudantes e orientadores, na qual para o primeiro é a necessidade para obtenção do título acadêmico que almeja, enquanto para o segundo é a oportunidade de incrementar seu currículo para uma concorrência por financiamento de pesquisa. São relações como qualquer outra humana, não desprovidas de interesse mútuo.

Academicamente, as trocas de ideias e experiências por meio de trabalhos de autoria coletiva demonstram sintonia fina para um determinado tema, o que enriquece o trabalho e permite a difusão de novas ideias em no mínimo duas instituições. Esse aumento de coautoria, em anos recentes, pode ser um indicador de uma maior qualidade nos trabalhos produzidos, representando o princípio da reciprocidade no qual todos trabalham por um desejo em comum.

$\mathrm{Na}$ colaboração entre orientadores e estudantes, identifica-se que as pesquisas desenvolvidas no mestrado, doutorado e pós-doutorado são fontes primitivas para os trabalhos 
publicados tanto nos anais do GT-1 dos Enancib quanto nos periódicos indexados na Brapci, o que está contribuindo para a grande produtividade de alguns pesquisadores da área, semelhante a comportamentos detectados em outros domínios do conhecimento.

A Tabela 3 apresenta o quantitativo de trabalhos em regime de colaboração com orientandos publicados nos anais do GT-1 dos Enancib e nos periódicos indexados na Brapci.

Tabela 3 - Trabalhos em regime de colaboração com orientandos.

\begin{tabular}{c|c|c}
\hline Ano & GT1 & Brapci \\
\hline 2003 & 4 & 0 \\
\hline 2004 & - & 0 \\
\hline 2005 & 3 & 0 \\
\hline 2006 & 3 & 0 \\
\hline 2007 & 4 & 1 \\
\hline 2008 & 8 & 1 \\
\hline 2009 & 7 & 0 \\
\hline 2010 & 6 & 2 \\
\hline 2011 & 8 & 8 \\
\hline 2012 & 11 & 2 \\
\hline 2013 & 8 & 10 \\
\hline 2014 & 7 & 2 \\
\hline 2015 & 6 & 4 \\
\hline 2016 & 19 & 9 \\
\hline 2017 & 15 & 11 \\
\hline 2018 & 17 & 19 \\
\hline Total & 126 & 69 \\
\hline
\end{tabular}

Fonte: Dados da pesquisa, 2018.

Para o enriquecimento curricular, os pesquisadores tendem a se comportar na busca da autoridade científica, poder acumulado e transmissão do conhecimento, sendo que para chegar ao status quo de pesquisador é necessário que o estudante construa uma rede de relações que o possibilite ascender na carreira ou lhe proporcione um cargo. Então, o que se pode observar nessa relação entre os pesquisadores é o interesse mútuo: o estudante almeja titulações em níveis mais elevados, ou a obtenção de um cargo de professor ou pesquisador; o professor orientador compete pela produtividade e obtenção da autoridade científica.

Com base nessas características, Silva e Hayashi (2012, p. 12) afirmam que o professor depende de sua reputação, frente aos demais colegas, para atrair estudantes de qualidade que lhes possibilitem conseguir "bolsas, convites, distinções, etc". Nessa perspectiva, foram identificados nessa pesquisa muitos pesquisadores, de status bolsista de pesquisa CNPq, que tiveram alunos com alta produtividade, em relação aos demais estudantes, e que os levaram a publicar mais de 10 artigos em diversos periódicos em um ano. 
Com exceção de 2007, os artigos em autoria única eram predominantes até o ano de 2013, quando o quadro se inverteu. Em termos percentuais, os artigos de autoria única alcançam $47 \%$ do total de publicações no referido GT-1, enquanto o percentual atingido pelos artigos em regime de colaboração é de $53 \%$ das publicações. É o reflexo do comportamento moderno da ciência: o estímulo a publicação por meio de parcerias acadêmicas para que se proporcione o seu desenvolvimento. Esse mesmo comportamento foi percebido nas publicações sobre a epistemologia e historiografia da Ciência da Informação nos periódicos indexados na Brapci.

Quanto à produtividade de artigos ao longo da carreira, percebeu-se que o tempo de carreira acadêmica não foi um fator forte para garantir que os pesquisadores mais antigos tivessem um número maior de artigos publicados. Constata-se que os pesquisadores mais novos estão em ascendência quanto a produção de artigos, enquanto boa parte dos pesquisadores da vanguarda estão diminuindo o ritmo de publicação. Alguns mantêm um padrão de publicação, como publicar em média dois artigos por ano; no entanto, há pesquisadores que chegaram a publicar 15 artigos em um ano.

Autores da vanguarda demonstram, a partir do currículo Lattes, que estão diminuindo o ritmo da produção acadêmica, tendo poucos orientandos em relação aos mais novos nos programas de pós-graduação; um indicador muito significante, pois parte significativa dos artigos tem origem nas produções de dissertações e teses.

Alguns intervalos sem publicação foram caracterizados como períodos de busca de titulação de pós-graduação por parte dos pesquisadores. Outras variáveis que afetaram a publicação de alguns pesquisadores do sexo feminino foram os períodos de maternidade, fazendo com que muitos intervalos de publicações se evidenciassem em suas timelines.

\section{CONSIDERAÇÕES FINAIS}

Estudar as estruturas institucionais que fomentam as pesquisas epistemológicas e histográficas da Ciência da Informação foi o alvo desta caçada científica, percebendo as pistas que configuram as instituições, as normas, as parcerias, a produtividade, os canais de comunicação, os perfis dos pesquisadores e as frentes de pesquisa. Uma busca com perspectivas descritivas de todo esse organismo que constitui o campo científico, mesmo consciente de possíveis riscos, como se deparar com um possível locus da luta pelo capital científico da concepção de Bourdieu (1983).

A caçada à produtividade dos pesquisadores acerca da temática epistemologia e historiografia da Ciência da Informação mostrou tendências de relações na produção dos 
trabalhos científicos, o que validou alguns preceitos de pesquisadores dos estudos métricos, assim como possibilitou novas configurações relacionadas aos novos modos de publicação científica e como isso influenciou para que a produtividade venha numa forte crescente nos últimos anos.

Dessa forma, percebeu-se que os pesquisadores se envolveram numa trama que busca o alinhamento entre ser produtivo e ser referência para os demais pesquisadores, na busca pela autoridade científica, assim como o investimento para o acúmulo do capital científico, necessário, segundo as estruturas normativas, para angariar recursos de fomento para suas pesquisas.

Quanto ao contex to geográfico dos autores do recorte dessa pesquisa, a região Sudeste tem a supremacia em todos os aspectos avaliados, porque tem, em seu território, os primeiros cursos de pós-graduação em Ciência da Informação e os primeiros grupos e linhas de pesquisa sobre a referida temática. Contudo, percebe-se uma ascensão dessa produtividade nas regiões Sul e Nordeste, que vêm com um número crescente de novos programas de pós-graduação na área. A região Norte ainda precisa de implementação de políticas públicas para que estudos relacionados à Ciência da Informação sejam desenvolvidos em instituições de pesquisa da região. A UnB carrega toda responsabilidade produtiva da região Centro-Oeste, o que demonstra que os outros estados da região também precisam da inserção de programas de pósgraduação na área.

Foram identificados 442 pesquisadores responsáveis por publicações acerca da temática em questão, sendo que 71,5\% desses publicaram apenas uma vez. Percebe-se, desse modo, que há uma alta rotatividade entre os pesquisadores no GT-1 dos Enancib, como já informava González de Gómez (2007), assim como nos periódicos indexados na Brapci. Isso pode configurar o caráter democrático dos veículos de comunicação científica no que se refere ao acompanhamento das pesquisas concluídas ou em andamento, como também pode caracterizar uma dispersão temática para os autores, ou seja, pesquisadores que se dedicam a outras temáticas que resultaram em uma discussão conceitual, o que permitiu as publicações sob o embasamento epistêmico e historiográfico da Ciência da Informação nesses canais de comunicação científica.

Na produção científica desses autores, o fato de o pesquisador estar no grupo de elite de uma determinada temática não significa que a qualidade do seu trabalho se evidencie. É necessário que sua produção tenha impacto referencial, o que o colocaria também no grupo de frente de pesquisa. Dessa forma, nesta pesquisa, alguns pesquisadores puderam compor, ao mesmo tempo, tanto o grupo de elite da temática em tela quanto o grupo frente de pesquisa, 
mas as configurações se deram de forma diferente para cada grupo. As primeiras posições do grupo de elite estão ocupadas por pesquisadores que entraram na pós-graduação a menos de 10 anos, enquanto os pesquisadores que ocupam as duas primeiras posições na frente brasileira de pesquisa da temática são professoras com mais de 30 anos de dedicação à docência da área, ambas pertencentes também ao grupo de elite.

Observou-se que o crescimento das publicações foi altamente influenciado pelo surgimento de novos periódicos na área, pelas regularidades de periocidade dos periódicos de um modo geral, bem como a institucionalização de novos programas de pós-graduação em Ciência da Informação, com seus instrumentos de publicação e divulgação científica.

No cumprimento das proposições iniciais dessa pesquisa, considera-se que os objetivos foram alcançados, pois a investigação sobre a produção e o desenvolvimento da Ciência da Informação, a partir das comunicações científicas dos estudiosos da epistemologia e historiografia da área, permitiu identificar os pesquisadores mais atuantes da temática e a descrição das relações estabelecidas entre os autores, além de levantar vários perfis acadêmicos dos referidos pesquisadores.

Em relação às circunstâncias da produção de trabalhos de autoria única ou em regime de colaboração, a maioria dos trabalhos, nos dois canais de comunicação científica, foi construída em colaboração, estabelecendo-se relações de coautoria entre orientadores e orientadores, além de parcerias entre pesquisadores dos mesmos grupos de pesquisa. Nesta pesquisa, foram identificados autores bolsistas de produtividade de pesquisa CNPq com alta produtividade, sendo que uma parte considerável dos seus artigos foi escrita com orientandos, o que permitiu que pesquisadores chegassem a publicar mais de 10 artigos por ano em periódicos da área.

Dessa maneira, foram estabelecidas relações de interesse mútuo, uma vez que os professores incrementam seus currículos a título de progressão profissional e fomento de suas pesquisas, na medida que os estudantes procuram sua inserção definitiva no meio acadêmico. Relações essas consideradas de poder, que podem se configurar, quando não inibidas, em ambientes insalubres de assédios morais.

Há também a relação entre parceiros de mesma instituição ou instituição diferente, mas que nutrem interesse comum acerca da temática, participam de mesmo grupo de pesquisa, ou participam conjuntamente de bancas de avaliações de pesquisa que derivam produções em colaboração. Essas relações podem figurar no campo da colaboração, o que contribui para o avanço coletivo da ciência, ou ambiente de competitividade, onde os sucessos são mais individuais do que coletivos. Esses pesquisadores, em sua maioria, estão em regência nas 
universidades, participando também de pesquisas e projetos de extensão. Percebeu-se que a biblioteconomia tem a maior representatividade na formação inicial desses pesquisadores, e a Ciência da Informação é responsável pela maioria das titulações de mestrado e doutorado dadas a esses autores.

A partir dos resultados desta pesquisa, algumas reflexões se fazem necessárias para que o progresso da produtividade sobre a temática tenha uma ascensão bem mais qualitativa do que quantitativa. É necessário um alinhamento com preceitos mais qualitativos na produção científica sobre a epistemologia e historiografia da Ciência da Informação. Essa é uma área muito sensível, cujas verdades se comprovam pelos construtos de ideias compostas por vieses historiográficos e conceituais.

Estudar a epistemologia se torna uma caça às ideias ou às características de produção acerca do tema, configura-se como o sustentáculo da essência temática, é a captura de perspectivas de pensamento, desenvolvendo a expansão do conhecimento. Isso justifica a extrema necessidade de manter os estudos epistemológicos atualizados, pois são base para o construto teórico e metodológico da área, o que permite visualizar as tendências de concepções conceituais e metodológicas. 


\section{REFERÊNCIAS}

ALVARES, Lillian; ARAUJO JUNIOR, Rogério Henrique de. Marcos históricos da ciência da informação: breve cronologia dos pioneiros, das obras clássicas e dos eventos fundamentais. Transinformação, Campinas, v. 22, n. 3, p. 195-205, dez. 2010.

ALVES, Rubem. Filosofia da ciência: introdução ao jogo e suas regras. 20. ed. São Paulo: Brasiliense, 1981.

ARAÚJO, Carlos Alberto Ávila. Correntes teóricas da ciência da informação. Ciência da informação, Brasília, DF, v. 38, n. 3, p. 192-204, set./dez. 2009.

ARAÚJO, Vania Maria Rodrigues Hermes de. Sistemas de recuperação da informação: nova abordagem teórico conceitual. 1994. 240 f. Tese (Doutorado em Comunicação) Faculdade de Comunicação, Centro de Filosofia e Ciências Humanas, Universidade Federal do Rio de Janeiro, Rio de Janeiro, 1994.

BARRETO, Aldo de Albuquerque. A condição da informação. São Paulo em perspectiva, São Paulo, v. 16, n. 3, p. 1-12, jul./set. 2002.

BASE DE DADOS DA CIÊNCIA DA INFORMAÇÃO (BRAPCI). 2018/2019. Disponível em: http://www.Brapci.inf.br/index.php. Acesso em: 10 nov. 2018 e jan./fev. 2019.

BOURDIEU, Pierre. O campo científico. In: BOURDIEU, Pierre. Sociologia. São Paulo: Atica, 1983. p. 122-155.

CAPURRO, Rafael. Epistemologia e ciência da informação. In: ENCONTRO NACIONAL DE PESQUISA EM CIÊNCIA DA INFORMAÇÃO - ENANCIB, 5. Anais [...] Belo Horizonte: ECI/UFMG, 2003. [não paginado].

CAPURRO, Rafael; HJØRLAND, Birger. O conceito de informação. Perspectivas em ciência da informação, Belo Horizonte, v. 12, n. 1, p. 148-207, jan./abr. 2007.

DUARTE, Emeide Nóbrega. - Análise da produção científica em gestão do conhecimento: estratégias metodológicas e estratégias organizacionais. 2003. 300 f. Tese (Doutorado em Administração) - Centro de Ciências Sociais Aplicadas, CCSA, UFPB - Universidade Federal da Paraíba, João Pessoa, 2003.

FIGUEIREDO, Nice. Paul Otlet e o centenário da FID. In: INSTITUTO BRASILEIRO DE INFORMAÇÃO EM CIÊNCIA E TECNOLOGIA. Organização do conhecimento e sistemas de classificação. Brasília: IBICT, 1996. p. 14-19.

FONSECA, João José Saraiva da. Metodologia da pesquisa científica. Fortaleza: UEC, 2002.

FOUCAULT, Michel. A ordem do discurso: aula inaugural no Collège de France, pronunciada em 2 de dezembro de 1970. Tradução de Laura Fraga de Almeida Sampaio. 5. ed. São Paulo: Loyola, 1999.

FREIRE, Gustavo Henrique de Araújo. Ciência da informação: temática, histórias e fundamentos. Perspectivas em ciência da informação, Belo Horizonte, v. 11, n. 1, p. 6-19, jan./abr. 2006. 
FREIRE, Isa Maria. Mediação da informação: um olhar sobre o portal LTi a partir literatura indexada na Brapci. Informação \& informação, Londrina, v. 19, n. 2, p. 23-45, maio/ago. 2014.

FREIRE, Isa Maria. Um olhar sobre a produção científica brasileira na temática epistemologia da ciência da informação. Tendências da pesquisa brasileira em ciência da informação, v. 1, n. 1, p. 1-31, 2008.

GABRIEL JUNIOR, Rene Faustino. Geração de indicadores de produção e citação científica em revistas de ciência da informação: estudo aplicado à base de dados BRAPCI. 2013. 140 f. Tese (Doutorado em Ciência da informação) - Faculdade de Filosofia e Ciências, UNESP - Universidade Estadual Paulista, Marília, 2014.

GIL, Antonio Carlos. Como elaborar projetos de pesquisa. 4. ed. São Paulo: Atlas, 2002.

GINZBURG, Carlos. Mitos, emblemas, sinais: morfologia e história. São Paulo: Cia. das Letras, 1989.

GONZÁLEZ DE GÓMEZ, Maria Nélida. GT1- Estudos Históricos e Epistemológicos da

Informação. Transcrição de palestra. 2007. Disponível em: http://slideplayer.com.br/slide/28 4026/. Acesso em: jul. 2020.

HASSAN-MONTERO, Yusef. Visualización y Recuperación de Información. In: ENCONTRO DE CIÊNCIAS E TECNOLOGIAS DA DOCUMENTAÇÃO E INFORMAÇÃO, 2., 2006. Porto. Anais [...]. Porto: Escola Superior de Estudos Industriais e de Gestão (Vila do Conde), 2006. [não paginada]. Disponível em: http://www.nosolousabilida d.com/hassan/visualizacion_y_recuperacion_de_informacion.pdf. Acesso em: 03 jul. 2020.

KOBASHI, Nair Yumiko; TALAMO, Maria de Fátima Gonçalves Moreira. Informação: fenômeno e objeto de estudo da sociedade contemporânea. Transinformação, Campinas, v. 15, n. esp., p. 7-21, dez. 2003.

LIMA, Larissa de Mello. A institucionalização cognitiva e social da Ciência da informação no Brasil: uma análise discursiva com base nos anais do GT-1 ENANCIB em sua primeira década. 2017. 104 f. Dissertação (Mestrado em Ciência da informação) - Faculdade de Filosofia e Ciências, UNESP - Universidade Estadual Paulista, Marília, 2017.

MARTINS, Dalton Lopes. Mapeamento da produção científica e participação dos autores nos anais do ENANCIB: uma análise a partir da correlação entre as redes de coautoria e redes de participação nos grupos de trabalho. RICI, Brasília, v. 6, n. 2, p. 71-88, ago./dez. 2013.

MATTELART, Armand. História da utopia planetária: da cidade profética à sociedade global. Porto Alegre: Sulina, 2002.

NAVES, Madalena Martins Lopes. Aspectos conceituais do browsing na recuperação da informação. Ciência da informação, Brasília, v. 27, n. 3, 1998. [não paginado].

NORONHA, Daisy Pires; MARICATO, João de Melo. Estudos métricos da informação: primeiras aproximações. Encontros Bibli: revista eletrônica de biblioteconomia e ciência da informação, Florianópolis, n. esp., 1. sem., p. 116-128, 2008. 
NUNES, Lucilene. Epistemologia e ciência da informação: um estudo das comunicações do GT-1 do ENANCIB. 2009. 132 f. Dissertação (Mestrado em Ciência da informação) Faculdade de Filosofia e Ciências, UNESP - Universidade Estadual Paulista, Marília, 2009.

ORTEGA, Cristina Dotta. Relações históricas entre Biblioteconomia, Documentação e Ciência da Informação. DataGramaZero, Rio de Janeiro, v. 5, n. 5, out. 2004. [não paginado].

RABELLO, Rodrigo. História dos conceitos e ciência da informação: apontamentos teóricometodológicos para uma perspectiva epistemológica Encontros Bibli: revista eletrônica de biblioteconomia e ciência da informação, Florianópolis, v. 13, n. 26, 2. sem. 2008.

RAYWARD, Warden Boyd. The origins of Information Science and the International Institute of Bibliograph/ International Federation for Information and Documentation (FID). Journal of the American Society for Information Science, v. 48, n. 4, p. 289-300, 1997.

RENDÓN ROJAS, Miguel Angel. La ciencia de la información en el contexto de las ciencias sociales y humanas. Ontología, epistemología, metodología e interdisciplina.

DataGramaZero, v. 9, n. 4, ago. 2008. [não paginado].

SARACEVIC, Tefko. Ciência da informação: origem, evolução e relações. Perspectivas em ciência da informação, Belo Horizonte, v. 1, n. 1, p. 41-62, jan./jun. 1996.

SILVA, Márcia Regina da; HAYASHI, Maria Cristina Piumbato Innocentini. O que Bourdieu tem a dizer à Bibliometria? In: SANTAREM SEGUNDO, José Eduardo; SILVA, Marcia Regina da; MOSTAFA, Solange Puntel Mostafa (Org). Os pensadores e a ciência da informação. 1. ed. Rio de Janeiro: E-Papers, 2012. p. 9-24.

YIN, Robert K. Pesquisa qualitativa do início ao fim. Porto Alegre: Penso, 2016.

URBIZAGASTEGUI ALVARADO, Ruben. Elitismo na literatura sobre a produtividade dos autores. Ciência da informação, Brasília, DF, v. 38, n. 2, p. 69-79, ago. 2009. 